\title{
Cultural influences on adoption of SMS advertising: A study of American and Taiwanese consumers
}

Received (in revised form): 10th December, 2007

\begin{abstract}
Alexander Muk
is an assistant professor of Advertising at Texas State University-San Marcos. He received his PhD from the University of Southern Mississippi. His main research interests include cross-cultural issues in wireless advertising, consumer behaviour and advertising effects.
\end{abstract}

Keywords SMS, advertising, culture, attitude, US, Taiwan

\begin{abstract}
This study examines whether cultural differences between countries have a significant impact on consumers' adoption of SMS advertising. Hofstede's cultural individualism/collectivism dimension is used to investigate whether culture is an important determinant of people's intentions to accept SMS advertising; Taiwan and the US, representing two different cultures, are selected in this study. The propositions presented in this study provide preliminary evidence that consumers' cultural orientations embedded in their belief systems may play an influential role in their decisionmaking processes. The findings of this study reveal that American consumers' decisions on accepting SMS ads via their mobile phones are solely based on attitudinal considerations whereas Taiwanese consumers' intentions to act are influenced by social norms as well as attitudinal factors.

Journal of Targeting, Measurement and Analysis for Marketing (2007) 16, 39-47. doi:10.1057/palgrave.jt.5750062
\end{abstract}

\section{INTRODUCTION}

Mobile access to the internet and the fast adoption of mobile telephony present another interactive medium for advertising. The ubiquity of the mobile phone extends the traditional media model of time-space. Mobile advertisers can deliver timely short message service (SMS) ads to consumers based on their demographic characteristics and geographic information. Worldwide, wireless advertisers have already integrated SMS into the media mix. ${ }^{1-3}$ SMS has started its ascent toward reaching critical mass as a direct marketing medium.

In the US, over 70 per cent of the population own a mobile phone ${ }^{4}$ and 53 per cent of them

Correspondence: Alexander Muk, School of Journalism and Mass Communication, Texas State University-San Marcos, 601 University Drive, 208 Old Main, San Marcos, TX 78666, USA.

Tel: +1512 2452656 ;

Fax: +1512 2457649 ;

E-mail: alexandermuk@hotmail.com have never sent a text message. ${ }^{5}$ In contrast, mobile phone subscribers in Taiwan have reached 100 per cent and most of them embrace SMS technology. ${ }^{6}$ Compared with Asian consumers, American consumers do not embrace SMS technology. An emerging field of mobile marketing research shows that the cultural orientation of a country influences its people's adoption of wireless technology. ${ }^{7,8}$ The fast adoption of mobile phones in Asia is cultural, not technological. ${ }^{9}$ Cultural values have long been recognised as a powerful force that shapes consumers' motivation and purchase decision. ${ }^{10}$ While attitude towards SMS advertising has been receiving increasing attention from both academics and practitioners, ${ }^{11-13}$ little research has attempted to examine the cultural impact on adoption of SMS advertising between countries. Thus, this research focuses on the potential cultural factors that may help explain adoption differences found between the US and Taiwan. 
The following research question is established to guide the study:

'Does a nation's culture influence its people's innovativeness in adopting SMS advertising?'

\section{LITERATURE REVIEW}

\section{SMS advertising}

SMS allows mobile phone users to send text messages of up to 160 characters to and from each other. ${ }^{14}$ American advertisers use a short code (five-digit) call-in system to make responding to SMS ads easier. To obtain a mobile coupon, consumers dial a short code to a company, who in turn can text them back via their mobile phones. ${ }^{15} \mathrm{~A}$ study by HarrisInteractive, ${ }^{16}$ a research firm, showed that about 7 per cent of the American mobile phone users would be interested in receiving SMS ads.

\section{Research model}

Prior research indicates that attitudes and social influences impact a person's propensity to adopt SMS advertising. ${ }^{17}$ Yet, little literature exists that draws a direct relationship between the cultural aspects of a country and consumers' intentions to adopt SMS advertising. The research model (see Muk and Babin) $)^{18}$ used in this study combined the aspects of Theory of Reasoned Action (see Ajzen and Fishbein) ${ }^{19}$ with aspects of Innovation Diffusion Theory ${ }^{20}$ to predict consumers' intentions to adopt SMS advertising. It should be noted that the objective of this research is not to test Muk and Babin's ${ }^{21}$ theoretical model. Rather, the model is used to examine the relationships among the constructs of the study to investigate the influence of culture on consumers' intentions to adopt SMS advertising. Past research shows that attitudes, social influences and intentions to opt in to SMS advertising are positively related. ${ }^{22}$ Figure 1 represents the research model.

\section{Cultural perspectives}

The patterns of national culture help explain the differences in consumer behaviour across nations and these differences in adopting an innovation are subscribed to individual nations' cultures. ${ }^{23,24}$ Understanding cultural differences is considered a prerequisite for successful international advertising. ${ }^{25}$ An innovative country is culturally homogeneous and has a highly concentrated population. ${ }^{26,27}$ Culture is values that are shared across people in a society and these underlying values influence individuals' attitudes and behaviours. ${ }^{28,29}$ Using Hofstede's cultural dimensions to map the values of national culture helps explain cultural differences in consumers' innovative behaviours across countries. ${ }^{30-32}$ Culture is a complex and multifaceted construct. Hofstede's ${ }^{33}$ individualism/collectivism stands out as an important dimension affecting consumers' adoption of innovation. ${ }^{34}$ Cross-cultural research consistently shows that individualists' behaviour is closely linked to attitudes, and collectivists' behaviour is closely linked to norms. ${ }^{35,36}$ In

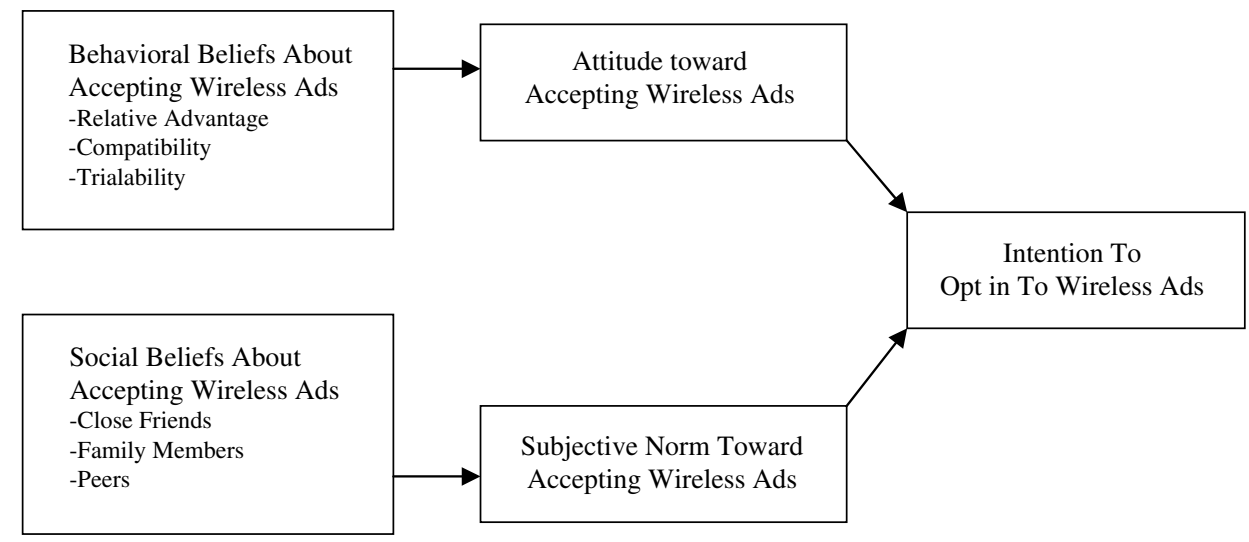

Figure 1: Research Model. Source: Muk and Babin (2006) 
individualist societies, ties between individuals are loose where people are concerned with themselves only. Individualists are motivated by self-interest and achievement of personal goals. In contrast, people living in collectivist societies are tightly integrated and are expected to look after the interests of their in-groups. Collectivist culture emphasises on sharing, cooperation and group harmony. Taiwan and the US are selected for this study because of their different cultural orientations. Taiwan represents a collectivist culture that tends to be more homogeneous and has a greater group orientation, whereas the US population displays heterogeneous and diversified characteristics of an individualist society.

Individualists believe that everyone has a right to privacy. ${ }^{37}$ American consumers are more concerned about privacy issues than their counterparts in Taiwan because Asian cultures do not place a high value on them. ${ }^{38}$ Attitudes and personality are internal factors that influence an individualist's adoption of an innovation..$^{39,40}$ Consumers living in individualist societies perceive SMS advertising as an intrusion into their privacy. ${ }^{41,42}$ The privacy concern suggested in the individualism dimension helps develop the first hypothesis, which is used to investigate the attitudinal differences in adoption of SMS advertising between American and Taiwanese consumers.

$\mathbf{H}_{1}$ : The relationship between attitudes and behavioural intentions to opt in to SMS ads will be stronger for Taiwanese consumers than for American consumers.

De Mooij ${ }^{43}$ pointed out that the locus of control in the decision-making process resides in the individual and that behaviour is a function of the individual's own action. This is a Western belief. On the other hand, external locus of control is part of collectivist cultures, where people are accustomed to other people making decisions for them. A fundamental difference between individualism and collectivism is between decision making by the individual or by the group. People living in a collectivist culture concentrate more on norms than on attitudes. ${ }^{44}$ They see interpersonal relationships as very important. In a collectivist culture, adopting innovation is a group process as coercive power may exist in interpersonal communication between group members. ${ }^{45,46}$ Consumers are inclined to accept opinions from people who interact frequently with them. In light of this argument, reference group and opinion leadership would have significant cultural effects on an individual's intention to adopt SMS ads. The influence of members of a group on the decision-making process helps develop the second hypothesis in this study.

\section{$\mathbf{H}_{2}$ : The relationship between social} influences and behavioural intentions to opt in to SMS advertising is stronger for Taiwanese consumers than for American consumers.

Text messaging has emerged as a new cultural phenomenon among mobile phone users worldwide, except America. In Taiwan, 65 per cent of the mobile phone subscribers use SMS every day ${ }^{47}$ and the SMS messages sent every month have surpassed 300 million. $^{48}$ A study by the Pew Internet \& American Life Project ${ }^{49}$ showed that only 35 per cent of American mobile phone users had sent a text message. In consumer innovation diffusion, heavy users with significant experience in similar product categories are more innovative. ${ }^{50}$ Thus, it is reasonable to believe that consumers' acceptance of SMS advertising may be influenced by their disposition toward using SMS as a form of mobile communication and their experience in using the medium.

\section{$\mathbf{H}_{3}$ : Taiwanese consumers will have stronger behavioural intentions to opt in to SMS ads than American consumers.}

The discussion, thus far, suggests that cultural factors may have a significant effect on the decision process that leads from consumers' attitudes toward SMS ads to social influences on signing up with wireless advertisers. The attributes of individualism and collectivism are the relative importance of attitudes versus social behaviours. To individualist Americans, determinants are 
attitudes and perceived rights. ${ }^{51}$ User privacy protection and easy opt-out mechanisms are trialability attributes that allow consumers to try out SMS ads. As Rogers ${ }^{52}$ suggested, trialability helps potential adopters reduce their perceived risk about the consequences of using an innovation. In this instance, one may expect that the trialability construct contributes most to the prediction of American consumers' adoption of SMS advertising.

\section{$\mathbf{H}_{4}$ : Trialability will be the strongest predictor of American consumers' intentions to adopt SMS advertising.}

On the other hand, the determinants of social behaviours for collectivist Taiwanese consumers are social norms and duties. ${ }^{53}$ In Taiwan, second to voice service, SMS is heavily used for communicating with friends. ${ }^{54}$ It is reasonable to believe that social pressures strongly influence Taiwanese consumers' intentions to adopt SMS advertising.

\section{$\mathbf{H}_{5}$ : Social influence will be the strongest predictor of Taiwanese consumers' intentions to adopt SMS advertising.}

\section{RESEARCH METHODOLOGY}

\section{Sampling}

A survey was conducted to examine cultural influences on adoption of SMS advertising between US and Taiwanese consumers. Judgment samples of university students under 25 years who subscribed to mobile phone services were purposively selected as sampling units because they fit the characteristics of the target population. University students are not only important market but they also have significant product experience. ${ }^{55}$ In the US, data were collected from two mediumsized universities located in the northeastern and southern regions. Taiwanese data were collected from two medium-sized universities located in the northern and middle regions of Taiwan. The samples consisted of 178 American and 198 Taiwanese students.

\section{Functional and instrument equivalence}

A thorough literature review showed that SMS technology was equally available to the members of both samples. Most respondents from the two countries essentially used SMS for communication purposes. Furthermore, advertisers had already used SMS technology to deliver advertising messages to mobile phone users in both countries. The substantive knowledge about the constructs under examination basically fulfilled the equivalent requirement for comparative research. ${ }^{56}$ Items were adopted from the original questionnaire in English developed by Muk and Babin. ${ }^{57}$ Two bilingual persons translated the questionnaire into Chinese and then another two bilingual persons translated it back into English. The translational equivalence was validated. ${ }^{58}$

\section{Measurement and scaling}

Three innovation attributes - relative advantage, compatibility and trialability — provide the measurement theory (see Muk and Babin). ${ }^{59}$ Relative advantage was measured with items representing perceived advantages due to (1) monetary savings; (2) convenience; and (3) collecting rewards by participating in SMS promotional activities. The compatibility dimension consisted of the following items: (1) the worry of disclosing one's mobile phone number to advertisers; (2) spam invasion; and (3) disclosing one's location information to advertisers. The salient consequences of the trialability dimension included the necessity of providing (1) easy opt-out mechanisms, (2) user privacy protection and (3) the convenience of opting out.

All belief items were measured on seven-point bipolar scales anchored with 'strongly disagree' (1) and 'strongly agree' (7). The evaluative component corresponding to the salient beliefs was measured by asking respondents to evaluate the consequences of each belief item on a sevenpoint bipolar scale ranging from -3 to +3 , with 0 as a midpoint. The bipolar scale anchors included very good/very bad, very difficult/very easy, very demanding/very effortless and very complicated/very simple. Conforming to reasoned 
action, attitude, social influence and intention constructs were included. Global attitude was measured on three seven-point semantic differential evaluative scales: very bad/very good, very wise/very foolish and very harmful/very beneficial. The direction of one of the attitude items was coded in reverse to restrict acquiescence bias. The salient referents including close friends, family members and peers were measured on a seven-point scale ranging from 'extremely unlikely' (1) to 'extremely likely' (7) the likelihood of opting in to SMS ads via their mobile phone with regard to each referent thought that they should or should not perform the behaviour. Motivation to comply with referents were measured on a seven-point scale ranging from 'extremely unlikely' $(-3)$ to 'extremely likely' $(+3)$ by having respondents to indicate how much they wanted to do what the referents thought they should do.

The subjective norm was measured on a sevenpoint scale ranging from 'extremely unlikely' (1) to 'extremely likely' (7) by using the standard Ajzen and Fishbein's ${ }^{60}$ wording: 'Most people who are important to me think I should opt in to SMS ads via my cell phone'. Intention was measured by asking respondents to respond to the statement 'intend to opt in to SMS ads via my cell phone in the next six months' on a sevenpoint scale ranging from 'extremely unlikely' (1) to 'extremely likely' (7).

\section{DATA ANALYSIS}

\section{Reliability and validity measures}

The coefficient alphas for each construct (attitude, social influence, relative advantage, compatibility, trialability) showed adequate convergence ranging from 0.70 to 0.89 . Using principal components analysis with varimax rotation to validate the constructs also resulted in a six-factor solution with eigenvalues greater than 1.0.

The standard Ajzen and Fishbien ${ }^{61}$ formula of theory of reasoned action was used to test the hypotheses. The behavioural belief variable that was used to predict attitude was the sum of products of salient beliefs and evaluations of those beliefs. Multiplying salient subjective norms by corresponding motivation to comply and then summing the products created the normative belief variable. Behavioural beliefs and social beliefs were used to predict the global attitude and the subjective norms, respectively.

\section{Test of hypotheses}

The correlation between global attitude and behavioural belief variables produced significant results: $r(176)=0.52, p<0.001$ and $r(196)=0.43$, $p<0.001$ for the US and Taiwanese data, respectively. Correlation between the social influence and subjective norm variables also produced significant results for the US data $(r(176)=0.69, p<0.001)$ and the Taiwanese data $(r(196)=0.39, p<0.001)$. The significant results allowed using global attitude and subjective norm as independent variables to test the hypotheses.

The regression analyses used to test the first and second hypotheses consisted of two independent models, one for each data set with the intention variable regressing on global attitude and subjective norm variables. Tables 1 and 2 summarise the regression results.

The $F$-tests for the two models were significant, $R^{2}=0.27, F(2,175)=24.6, p>0.001$, and $R^{2}=0.36, F(2,195)=55.3, p>0.001$, for the US and Taiwanese data, respectively.

$H_{1}$ :The first hypothesis predicted that the relationship between attitudes and behavioural intentions to opt in to SMS ads would be stronger for Taiwanese consumers than for American consumers. Comparison of the beta weights of the attitude variable in each model did not support the hypothesis (US data, $\beta=0.460$, and Taiwanese data, $\beta=0.409$ ). A subsequent t test of the mean attitude scores also did not yield a significant result, $\mathrm{t}(374)$, NS.

Table 1: Summary of regression analysis for variables predicting behavioural intentions

\begin{tabular}{lcll}
\hline (US, $\boldsymbol{N = 1 7 8 )}$ & & & \\
\hline Variable & $\boldsymbol{B}$ & SE & $\boldsymbol{\beta}$ \\
\hline Attitude & 0.193 & 0.029 & $0.460^{\star \star \star *}$ \\
Subjective norm & -0.107 & 0.113 & 0.066 \\
\hline
\end{tabular}

Note: $R^{2}=0.266$.

${ }^{* \star *} p<0.001$. 
Table 2: Summary of regression analysis for variables predicting behavioural intentions

\begin{tabular}{llll}
\hline (Taiwan $\boldsymbol{N = 1 9 8 )}$ & & & \\
\hline Variable & $\boldsymbol{B}$ & SE & $\boldsymbol{\beta}$ \\
\hline Attitude & 0.189 & 0.029 & $0.409^{\star \star \star}$ \\
Subjective norm & 0.321 & 0.069 & $0.297^{\star \star \star}$ \\
\hline
\end{tabular}

Note: $R^{2}=0.362$.

${ }^{* *} p<0.001$.

$\mathrm{H}_{2}$ :The relationship between subjective norm and behavioural intentions would be stronger for Taiwanese consumers than for American consumers. The beta weight of the subjective norm variable in the Taiwanese data was significant $(\beta=0.297, p<0.001)$ whereas the Beta weight of the US data was not significant $(\beta=0.066)$. A subsequent $t$-test also showed significant results, $t(374)=9.643, p<0.001$, of the mean subjective norm scores (US $M=1.59$, Taiwan $\mathrm{M}=2.84)$. Therefore, $\mathrm{H}_{2}$ was supported.

$H_{3}$ : The third hypothesis predicted that intentions to opt in to SMS ads were stronger for the Taiwanese consumers than for the Americans. The significant results of the $t$-statistics, $t(374)=2.77, p=0.006$, supported the third hypothesis (Taiwan, $M=2.44, U S, M=1.99$ ).

Stepwise regression analyses were used to test hypotheses 4 and 5 . In the US data regression, trialabililty, compatibility, relative advantage and social influence were entered in step 1, step 2, step 3 and step 4 , respectively. The order of entering the variables in the Taiwanese data regression was in reverse.

Tables 3 and 4 present the stepwise regression results.

$\mathrm{H}_{4}$ : This hypothesis suggested that the trialability dimension would be the strongest predictor of American consumers' intentions to adopt SMS advertising. Controlling for compatibility, relative advantage and social influence, trialability predicted a significant proportion of variance in intention, $R^{2}$ change $\left.=0.17, F(1,169)=33.7, p<0.001\right)$.

Therefore, $\mathrm{H}_{4}$ is supported.

$H_{5}$ : The significant regression results showed that social influence was the strongest predictor of Taiwanese consumers' intentions to adopt SMS advertising, $R^{2}$ change $=0.07, F(1,196)=14$, $p<0.001$ ), after controlling for the effects of the attitudinal variables. $\mathrm{H}_{5}$ was also supported.
Table 3: Summary of stepwise regression analysis for variables predicting intentions

\begin{tabular}{lrll}
\hline (US, $\boldsymbol{N = 1 7 8 )}$ & & & \\
\hline Variable & $\boldsymbol{B}$ & SE & $\boldsymbol{\beta}$ \\
\hline Step1 & & & \\
$\quad$ Trialability & 0.035 & 0.006 & $0.408^{\star \star \star}$ \\
Step 2 & & & \\
$\quad$ Trialability & 0.032 & 0.006 & $0.374^{\star \star \star}$ \\
$\quad$ Compatibility & 0.014 & 0.005 & $0.202^{\star \star}$ \\
& & & \\
Step 3 & & & \\
$\quad$ Trialability & 0.023 & 0.008 & $0.263^{\star \star}$ \\
$\quad$ Compatibility & 0.013 & 0.005 & $0.180^{\star}$ \\
$\quad$ Relative advantage & 0.022 & 0.012 & $0.175^{\star}$ \\
& & & \\
Step 4 & & & \\
$\quad$ Trialability & 0.023 & 0.008 & $0.262^{\star}$ \\
$\quad$ Compatibility & 0.013 & 0.005 & $0.180^{\star}$ \\
$\quad$ Relative advantage & 0.023 & 0.012 & 0.176 \\
$\quad$ Social influence & -0.001 & 0.012 & -0.175 \\
\hline
\end{tabular}

Note: $R^{2}=0.17$ for Step $1 ; \Delta R^{2}=0.21$ for Step 2; $\Delta R^{2}=0.22$ for Step 3; $\Delta R^{2}=0.22$ for Step 4 .

${ }^{\star * *} p<0.001 ;{ }^{* *} p<0.01 ;{ }^{*} p<0.05$.

Table 4: Summary of stepwise regression analysis for variables predicting intentions

\begin{tabular}{|c|c|c|c|}
\hline \multicolumn{4}{|l|}{ (Taiwan, $N=198$ ) } \\
\hline Variable & $B$ & SE & $\beta$ \\
\hline \multicolumn{4}{|l|}{ Step1 } \\
\hline Social influence & 0.029 & 0.008 & $0.259^{\star \star \star}$ \\
\hline \multicolumn{4}{|l|}{ Step 2} \\
\hline Social influence & 0.027 & 0.008 & $0.238^{\star \star \star}$ \\
\hline $\begin{array}{l}\text { Relative } \\
\text { advantage }\end{array}$ & 0.032 & 0.009 & $0.233^{\star \star \star}$ \\
\hline \multicolumn{4}{|l|}{ Step 3} \\
\hline Social influence & 0.026 & 0.008 & $0.235^{\star \star \star}$ \\
\hline $\begin{array}{l}\text { Relative } \\
\text { advantage }\end{array}$ & 0.034 & 0.009 & $0.233^{\star \star \star}$ \\
\hline Compatibility & 0.011 & 0.005 & $0.143^{*}$ \\
\hline \multicolumn{4}{|l|}{ Step 4} \\
\hline Social influence & 0.026 & 0.008 & $0.234^{\star \star \star}$ \\
\hline $\begin{array}{l}\text { Relative } \\
\text { advantage }\end{array}$ & 0.032 & 0.011 & $0.232^{\star *}$ \\
\hline Compatibility & 0.011 & 0.005 & $0.142^{*}$ \\
\hline Triabalility & 0.001 & 0.006 & 0.019 \\
\hline
\end{tabular}

Note: $R^{2}=0.07$ for Step $1 ; \Delta R^{2}=0.12$ for Step 2; $\Delta R^{2}=0.14$ for Step 3; $\Delta R^{2}=0.14$ for Step 4 .

${ }^{\star \star *} p<0.001 ;{ }^{\star *} p<0.01 ;{ }^{*} p<0.05$.

\section{DISCUSSION}

The results of the five hypotheses provide preliminary evidence to answer the research question that a nation's culture does influence its 
people's innovativeness in adopting SMS advertising. Social pressure is less likely to affect American respondents' innovation decisions. This is consistent with the cultural characteristics of individualists who are more independent and tend to make their own decisions. In contrast, social influence appears to be a coercive power that may compel Taiwanese respondents to conform to group behaviour. This supports de Mooij's ${ }^{62}$ argument that collectivists are usually influenced by their close friends in adopting new ideas. The findings also suggest that American and Taiwanese consumers do not differ significantly in their attitudes toward the new medium. They both show unfavourable attitudes (US data $M=-1.43$ and Taiwan data $\mathrm{M}=-0.77$ ) toward the SMS advertising. This could be explained by the growing negative attitudes that consumers hold toward advertising. ${ }^{63}$

The trialability construct is the strongest predictor of Americans' intentions affirming their perceived risk of losing their personal privacy. As the Theory of Psychological Reactance ${ }^{64}$ suggests, consumers may react aversively if they believe that their freedom is being threatened. The trailability-intention relationship indicates the importance of allowing consumers to try to accept SMS ads with no hassle. This also suggests that privacy is an important cultural value in individualist societies.

Social influence is the strongest predictor of Taiwanese consumers' intentions. The collectivist characteristics shown in Taiwanese consumers are consistent with Hofstede's ${ }^{65}$ findings that collectivist people usually reinforce their social networks by conforming to group behaviour. Consistent with the hypothesis that heavy users with significant experience in similar product categories are more innovative, ${ }^{66}$ Taiwan respondents have a stronger intention to adopt the new medium than their American counterparts. Attitude and social influence significantly predict intentions to act for both cultures with regard to individualism/collectivism.

\section{Managerial implications}

Congruent with research involving cross-cultural consumer behaviour, this study found differences between two countries in terms of cultural influences on consumers' intentions to adopt SMS advertising. The findings showed that cultural values are important factors affecting consumer acceptance of SMS ads. American consumers' intentions to opt in to SMS advertising are predominantly influenced by their concern for privacy. The concern is apparently directed more to the trustworthiness of the SMS advertisers than to the medium. American mobile advertisers should pay close attention to privacy concerns that consumers have in SMS advertising. To persuade American consumers to accept SMS ads via their mobile phones, the opt-in and out mechanisms should not be too restrictive so that a sense of trust and participation is encouraged. In this respect, the medium is more appropriate for leading brands than less known brands because huge brands can leverage their brand equity on building brand trust. According to the attribution theory, ${ }^{67}$ advertising for brands that consumers consider as valuable is likely to be perceived as more trustworthy because they reinforce the linkage between belief and behaviours.

The significant effect of social pressure on Taiwanese consumers indicates that the strong force of group conformity cannot be ignored in markets where consumers are more group oriented. Based on the concept of group influence processes, Taiwanese mobile advertisers should fully utilise the interactive nature of SMS technology and develop promotional programmes based on group-oriented activities to get opinion leaders to drive product adoption. Promotional strategy can be built around the concept that the service is positioned as being offered especially to the members of the group. For international advertisers, this study revealed that there is no one size fits all type of SMS advertising strategy. Understanding cultural sensitivity and cultural adaptation is important to the success of implementing an SMS advertising strategy in the global advertising arena.

\section{Limitations and future research}

One limitation is generalisability. Although the convenience sampling used in this study addressed the primary target of mobile marketing, 
diversified and nonstudent samples from different regions of the US and Taiwan may provide adequate data and variability to explore how cultures impact susceptibility toward attitudinal and social influences on acceptance of SMS advertising. As demographic variables such as age and education were controlled for this study, future researchers should consider using a random sampling technique and broader segments. Thus, a general picture of how all consumers will view SMS advertising can be drawn from analysing the similarities and differences between segments.

Although this study has successfully replicated Muk and Babin's ${ }^{68}$ research design, an experimental examination of the hypotheses would provide more confidence in the processes under study than a survey design that rests on a self-reported questionnaire instead of consumer actual behaviour. Future research should incorporate salient cultural features into the attitude and belief scales. Having culture measured on scales rather than via assumptions based on established cultural indexes is a stronger research approach. This study looked at only one dimension of cultural difference between the US and Taiwan. Past cultural research suggests that the level of uncertainty avoidance affects consumers' adoption of an innovation as well. ${ }^{69}$ Including this cultural dimension may help identify the moderating effects of cultural dimensions as well as measure the strength of particular cultural variables in predicting intention to sign up with SMS advertisers. Future researchers may also choose to replicate this study by using countries other than those under examination in this study or to perform a similar study in order to explore the relationship between culture and acceptance of other types of wireless advertising.

\section{CONCLUSION}

Muk and Babin's ${ }^{70}$ model provides a useful and comparatively straightforward basis for explaining consumer innovation decisions on accepting SMS ads between two discrete cultures. This is the first cross-cultural research in the belief and attitude tradition that focuses on antecedents of intention related to the adoption of SMS advertising. Preliminary evidence reveals that American consumers' decisions on accepting SMS ads via their mobile phones are solely based on attitudinal considerations whereas Taiwanese consumers' intentions to act are influenced by social norms as well as attitudinal factors. The two samples do not, however, exhibit substantial differences in the importance of personal attitudes in determining behavioural intentions, except with the effect of social influence.

The findings illustrate the relative importance of social influence in behavioural formation in a collectivist culture. It is also important to point out that the functioning of the processes implied by the theory of reasoned action model ${ }^{71}$ could be attributed to the effects of cultural values embedded in consumer belief systems. The propositions presented in this study shed light on the cultural differences between the US and Taiwan. Contrary to popular beliefs, high penetration rates of mobile phone (hardware) and SMS technology (software) in Taiwan do not make its consumers more receptive toward SMS ads. That American and Taiwanese consumers exhibit equally unfavourable attitudes toward SMS advertising may be attributed to their perceived aversive social consequences of opting in to the new medium.

\section{References}

1 International Data Corporation (2006) 'Marco polo survey 2005', http://www.idc.com/getdoc.jsp?containerId=pr2006_03_ 03_130022, retrieved 29th March, 2006.

2 Okazaki, S. (2005) 'Mobile advertising adoption by multinationals', Internet Research, Vol. 15, No. 2, pp. 160-180.

3 Cuneo, A. (2004) 'Marketers dial into messaging', Advertising Age, 1 November, p. 18.

4 Tedeschi, B. (2007) 'Reaching more customers with a simple text message', The New York Times, 16 July, http://www.nytimes. com/2007/07/16/business/media/16ecom.html, retrieved 16th July, 2007.

5 International Data Corporation (2006) 'Mobile entertainment services not particularly popular among American consumers', http://www.idc.com/getdoc.jsp?containerId=prUS20475506, retrieved 20th Novemeber, 2007.

6 FIND (2007) 'The mobile internet in Taiwan-Q42006', http:// www.find.org.tw/eng/newsprint.asp?pos=0\&subjectid=17\&msgi $\mathrm{d}=294$, retrieved 20th November, 2007.

7 Mao, E., Srite, M., Thatcher, J. B. and Yarpark, O. (2005) 'A research model for mobile phone service behavior: Empirical validation in the US and Turkey', Journal of Global Information Technology, Vol. 8, No. 4, pp. 7-28.

8 Tse, T., Tiong, J. and Kangaslahti, V. (2004) 'The effect of cultural norms on the uptake of information and communication 
technologies in Europe: A conceptual analysis', International Journal of Management, Vol. 21, No. 3, pp. 382-392.

9 Fowler, G. (2005) 'Asia's mobileads; US firms study what flies on hot medium and why: And how to try it at home', The Wall Street Journal, 25th April, p. B1.

10 De Mooij, M. (1998) 'Global Marketing and Advertising: Understanding Cultural Paradoxes', Sage, Thousand Oaks.

11 Muk, A. and Babin, J. B. (2006) "US consumers' adoptionnonadoption of mobile SMS advertising", International Journal of Mobile Marketing, Vol. 1, No. 1, pp. 21-29.

12 Scharl, A., Dickinger, A. and Murphy, J. (2004) 'Diffusion and success factors of mobile marketing', Electronic Commerce Research and Applications, Vol. 4, pp. 159-173.

13 Tsang, M., Ho, S. C. and Liang, T. P. (2004) 'Consumer attitudes toward mobile advertising: An empirical study', International Journal of Electronic Commerce, Vol. 8, No. 3, pp. 65-78.

14 Bayne, K. (2002) 'Marketing Without Wires', John Wiley \& Sons, New York.

15 Noguchi, Y. (2003) 'New ad frontier: Cellphones', The Washington Post, 8th November, p. A01.

16 HarrisInteractive (2006) 'About one quarter of current mobile phone subscribers support incentive-based advertising', http:// www.harrisinteractive.com/news/allnewsbydate.asp?/ NewsID=1109, retrieved 28th October, 2004.

17 Muk and Babin (2006) op. cit.

18 Ibid.

19 Ajzen, I. and Fishbein, M. (1980) 'Understanding Attitudes and Predicting Social Behavior', Prentice-Hall, Englewood Cliffs.

20 Rogers, E. (1995) 'Diffusion of Innovations', 4th edn, The Free press, New York.

21 Muk and Babin (2006) op. cit.

22 Ibid.

23 De Mooij, M. (2000) 'The future is predictable for international marketers', International Marketing Review, Vol. 17, No. 2/3, pp. 103-114.

24 Takada, H. and Jain, D. (1991) 'Cross-national analysis of diffusion of consumer durable goods in pacific rim countries', Journal of Marketing, Vol. 55, No. 2, pp. 8-54.

25 Wells, W., Burnett, J. and Moriarty, S. (2006) 'Advertising Principles \& Practice', 6th edn, Prentice-Hall, Upper Saddle.

26 Dekimpe, M., Parker, P. and Sarvary, M. (2000) 'Globalization: Modeling technology adopting timing across countries', Technological Forecasting and Social Change, Vol. 63, pp. 25-42.

27 Rogers (1995) op. cit.

28 Straub, M., Loch, K., Evaristo, R., Karahanna, E. and Srite, M. (2002) 'Toward a theory-based measurement of culture', Journal of Global Information Management, Vol. 10, No. 1, pp. 13-23.

29 Hofstede, G. (1991) 'Cultures and Organizations: Software of the Mind', McGraw Hill, London.

30 La Ferle, C., Edwards, S. and Mizuno, Y. (2002) 'Internet diffusion in Japan: Cultural considerations', Journal of Advertising Research, Vol. 42, No. 2, pp. 65-79.

31 De Mooij (2000) op. cit.

32 Samiee, S. (1998) 'The internet and international marketing: Is there a fit', Journal of Interactive Marketing, Vol. 12, No. 4, pp. 5-21.

33 Hofstede (1991) op. cit.

34 De Mooij (2000) op. cit.

35 Bagozzi, R., Wong, N., Abe, S. and Bergami, M. (2000) 'Cultural and situational contingencies and the theory of reasoned action: Application to fast food restaurant consumption', Journal of Consumer Psychology, Vol. 9, No. 2, pp. 97-106.
36 Lee, C. and Green, R. T. (1991) 'Cross-cultural examination of the fishbein behavioral intentions model', Journal of International Business Studies, Vol. 22, No. 2, pp. 89-305.

37 Hofstede (1991) op. cit.

38 De Mooij (1998) op. cit.

39 Ibid.

40 Triandis, H. (2004) 'The many dimensions of culture', Academy of Management Executive, Vol. 8, No. 1, pp. 88-93.

41 Barnes, S. (2002) 'Wireless digital advertising: Nature and implications', International Journal of Advertising, Vol. 21, No. 3, pp. 399-420.

42 International Data Corporation Aisa-Pacific (2002) 'Unwiring the internet: An end-user perspective', http://www.idc.com.sg/ Press/2002/AP-PR-unwiring.htm, retrieved 24th September, 2003.

43 De Mooij (1998) Op. Cit.

44 Triandis (2004) op. cit.

45 De Mooij (1998) op. cit.

46 Gatignon, H. and Robertson, T. (1991) 'Innovative decision processes', in Robertson, T. and Kassarjian, H. (eds), 'Handbook of Consumer Behavior', Prentice-Hall, Englewood Cliffs, pp. 316-348.

47 International Data Corporation (2006) op. cit.

48 FIND (2007) Op. Cit.

49 Pew internet \& American life project (2006) 'Pew internet data memo', http://www.pewinternet.org/pdfs/PIP_cell_phone_ study.pdf.

50 Gatignon, H. and Robertson, T. (1985) 'A prepositional inventory for new diffusion research', Journal of Consumer Research, Vol. 11, pp. 849-867.

51 Triandis (2004) op. cit.

52 Rogers (1995) op. cit.

53 Triandis (2004) op. cit.

54 Ho, J. (2004) 'Yams see bright future for online adverts', The Taipei Times, http://www.taipeitimes.com/News/biz/ archives/2004/01/14/2003087598, retrieved 20th January, 2004.

55 Muk and Babin (2006) op. cit.

56 Douglas, S. P. and Craig, S. (1983) 'International Marketing Research', Prentice-Hall, Englewood Cliffs.

57 Muk and Babin (2006) op. cit.

58 Brislin, R.W. (1986) 'The wording and translation of research instruments', in Lonner, W.J. and Berry, J.W. (eds), 'Field Methods in Cross-Cultural Research', Sage, Beverly Hills, pp. $137-164$.

59 Muk and Babin (2006) op. cit.

60 Ajzen and Fishbein (1980) op. cit.

61 Ibid.

62 De Mooij (1998) op. cit.

63 Zanton, E. (1981) 'Public attitudes toward advertising', in Hunt, K. (ed.), 'Advertising in a New Age, 'Proeceedings of the Annual Conference fo the American Academy of Advertising', Brigham Young University Press, Provo, pp. 141-146.

64 Mowen, J. and Minor, M. (2001) 'Consumer Behavior: A Framework', Prentice-Hall, New Jersey.

65 Hofstede (1991) op. cit.

66 Gatignon and Robertson (1985) op. cit.

67 Mowen and Minor (2001) op. cit.

68 Muk and Babin (2006) op. cit.

69 De Mooij (2000) op. cit.

70 Muk and Babin (2006) op. cit.

71 Ajzen and Fishbein (1980) op. cit. 